
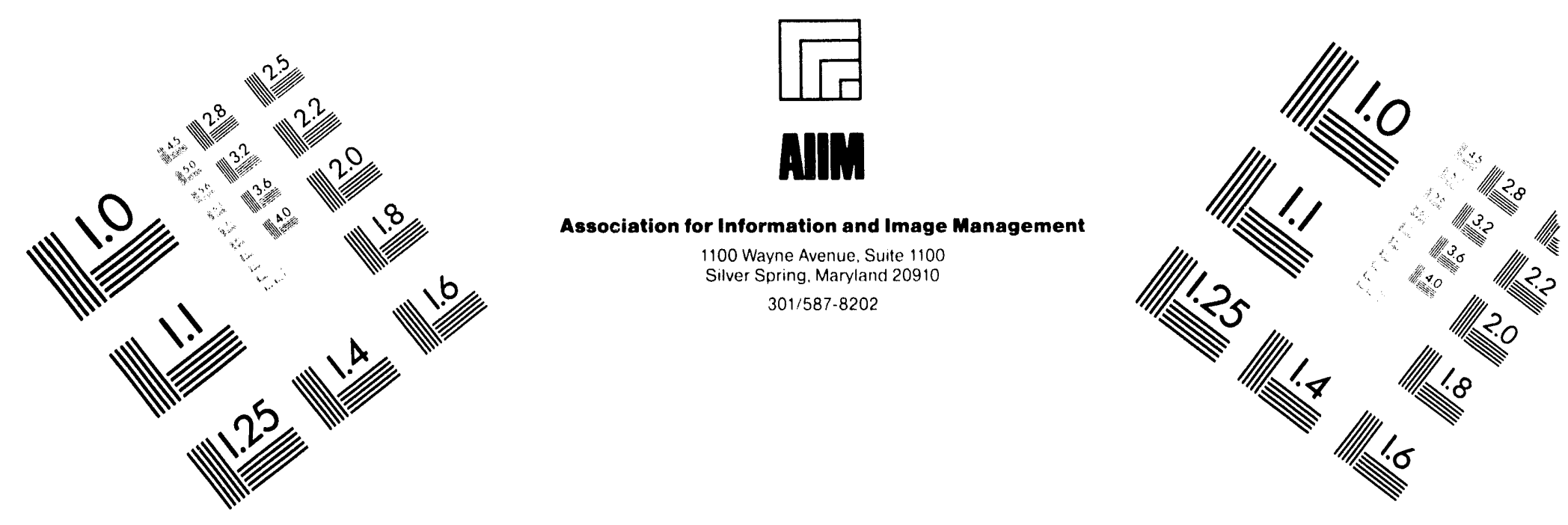

\title{
Centimeter
}

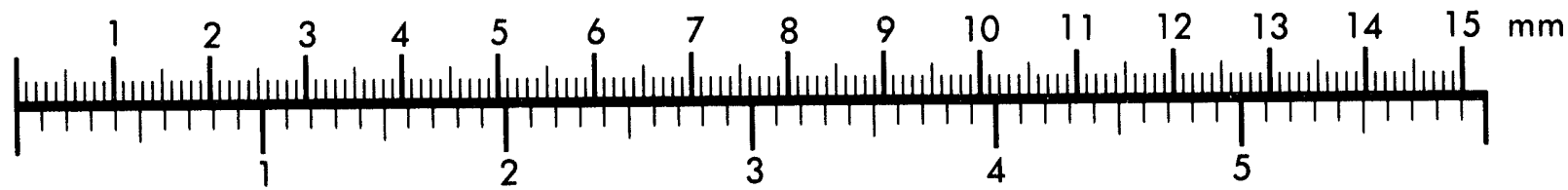

Inches
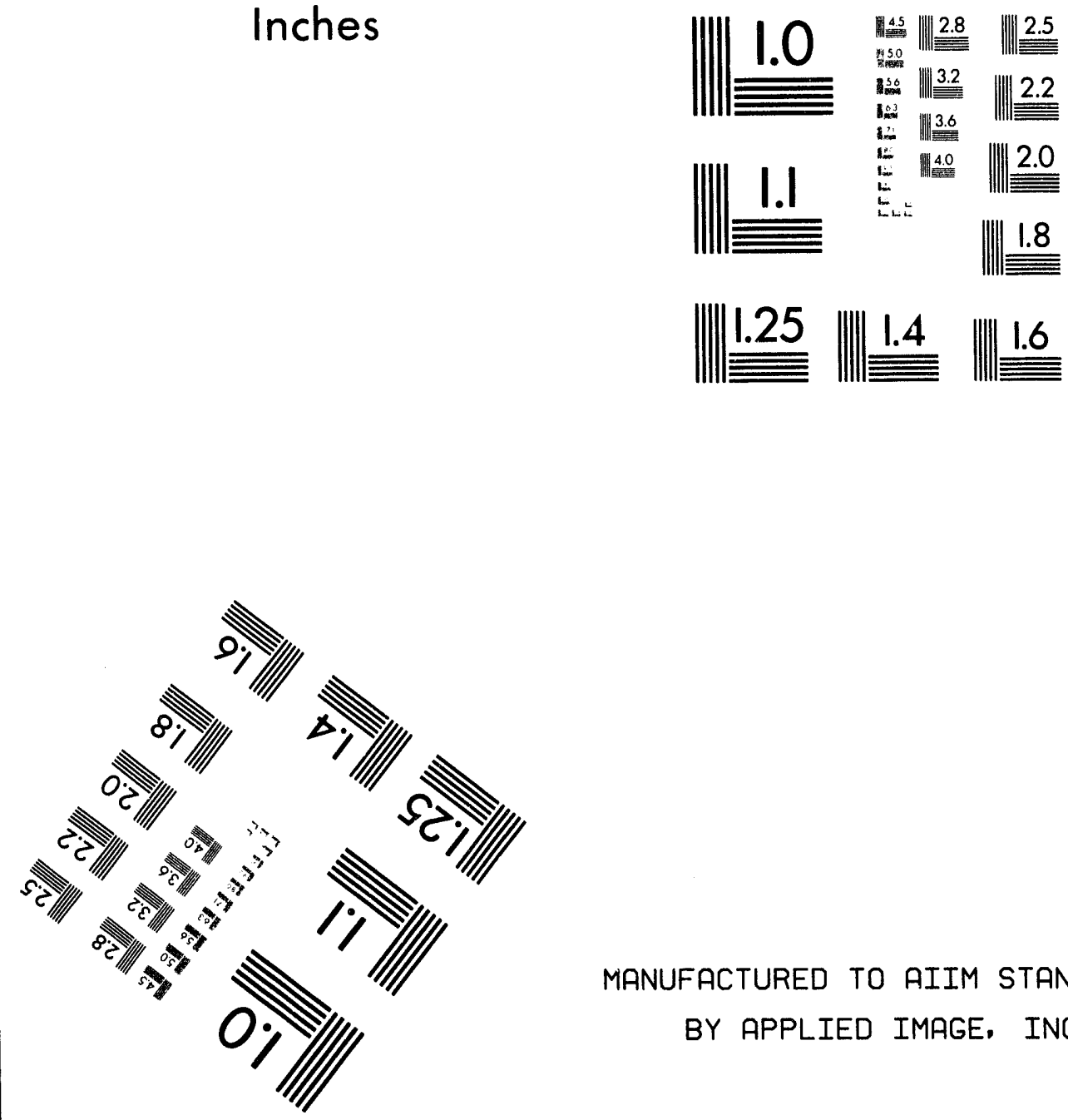

MANUFACTURED TO AIIM STANDARDS

BY APPLIED IMAGE, INC.

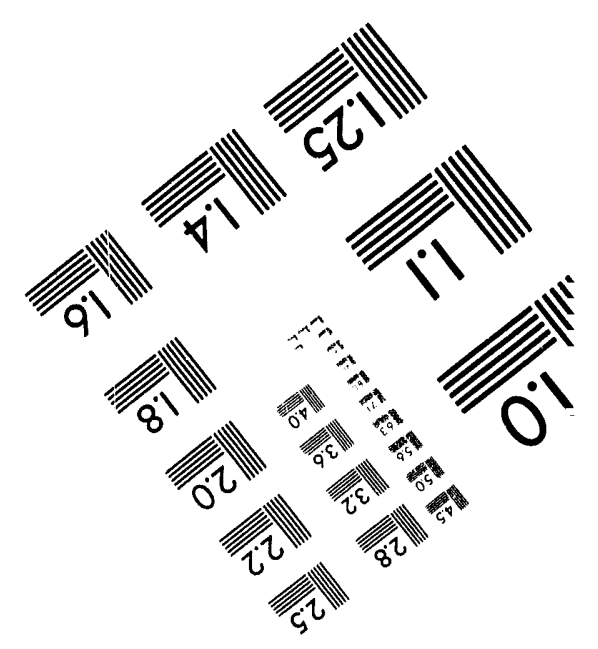



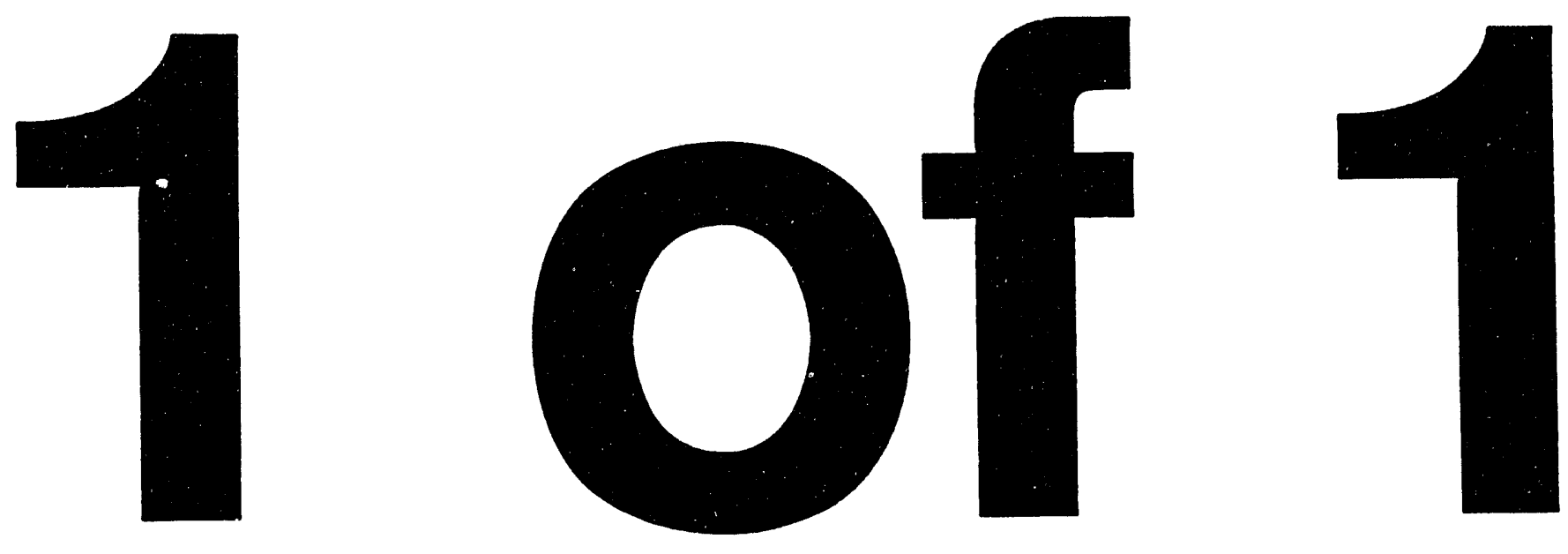


\title{
Conf-94.0769--6
}

PNL-SA-23559

\begin{abstract}
AN EXPERIMENTAL AND NUMERICAL STUDY OF THE MODIFICATIONS OF MIXED-LAYER STRUCTURE BY INHOMOGENEOUS SURFACE FLUXES AND SECONDARY CIRCULATIONS
\end{abstract}

S. Zhong
J. C. Doran

July 1994

Presented at the

6th Conference of Mesoscale Processes

July 18-22, 1994

Portland, Oregon

Prepared for

the U.S. Department of Energy

under Contract DE-AC06-76RLO 1830

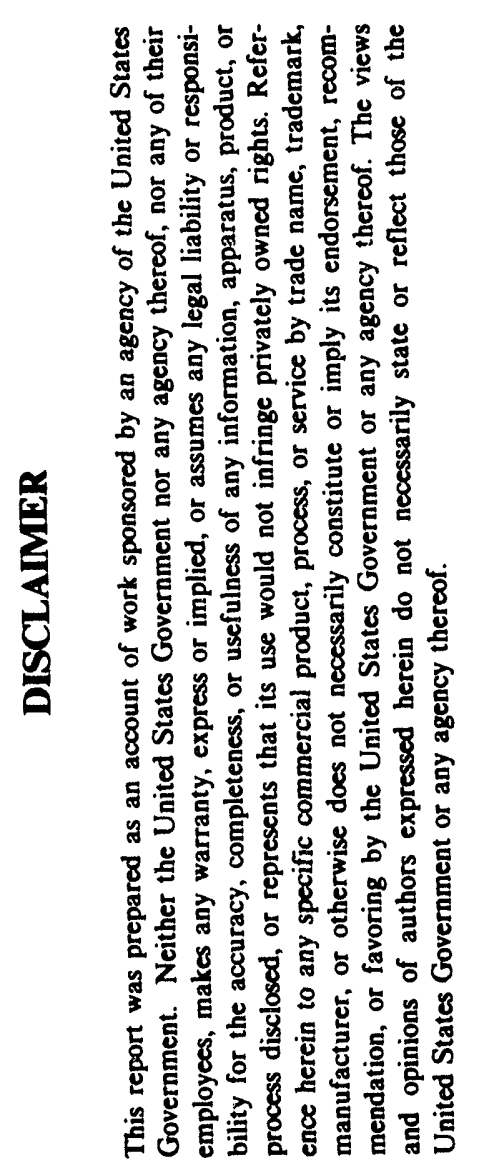

Pacific Northwest Laboratory

Richland, Washington 99352 


\title{
P 2.20
}

\section{An Experimental and Numerical Study of the Modifications of Mixed-Layer Structure by Inhomogeneous Surface fluxes and Secondary Circulations}

\author{
Shiyuan Zhong and J. C. Doran \\ Pacific Northwest Laboratory \\ Richland, Washington
}

\section{INTRODUCTION}

The problem of scale interactions in the planetary boundary layer (PBL), i.e., how forcing mechanisms of differing spatial and temporal scales affect the properties of the PBL, has been a subject of considerable interest for some time. One aspect of this problem that has received increasing attention in recent years is the representation, in mesoscale and general circulation models, of the effects of subgridscale inhomogeneities in surface properties. Differences in sensible and latent heat fluxes between adjacent areas can result in secondary circulations, modifications to the boundary layer structure, and the transport of heat and moisture from one area to another. Despite their potential influence on local PBL properties, such effects can not be resolved by numerical models whose scale is too coarse; thus, suitable parameterizations that account for these phenomena are needed.

To illustrate the effects of surface inhomogeneities on PBL structure, many mesoscale modeling studies (e.g., Segal et. al., 1988; Yan and Anthes, 1988; Avissar and Chen, 1993) have considered idealized conditions in which adjacent surface patches have sharply contrasting but locally uniform properties, such as soil moisture, that result in corresponding contrasts in sensible and latent heat fluxes. If these contrasting patches are made sufficiently large, e.g., $50-100 \mathrm{~km}$, the secondary circulations that arise can drastically affect the structure and dynamics of the PBL. This alteration makes the parameterizations of surface fluxes that are used in more uniform conditions inapplicable. However, such surface conditions are not commonly found in the real world; instead, patches are usually considerably smaller and nonuniform. In this paper we present some results of wind and temperature measurements over an area with significant variations in surface fluxe.; on scales of

* Corresponding author address: S. Zhong, MSIN: K6-11, P. O. Box 999, Richland, WA 99352.
$O(10 \mathrm{~km})$. We then use fine resolution numerical simulations to show how synoptic, topographical, and thermal forcing combine to affect the properties of the PBL in the region. Specifically, we consider the relative importance of topography and land-use differences on the generation of secondary circulations and on the depth of the mixed layer, and we show how these effects are modified by synoptic wind fields. Implications for coarser resolution models are also discussed.

\section{MEASUREMENTS}

From June 4 to June 15 of 1992, a field experiment was carried out near the town of Boardman in northcentral Oregon. The region was characterized by two sharply contrasting land types: a semi-arid shrubsteppe area and irrigated farms. Radiosondes and sodars were used to measure the temperature and wind profiles of the boundary layer over adjacent steppe and farm areas, and arrays of anemometers, temperature sensors, and eddy correlation instruments were used to obtain near-surface wind and temperature data and sensible and latent heat fluxes. Figure 1 shows a schematic diagram of the experiment site and the locations of the instruments.

During the experiment period, the steppe area was quite dry while the farm area was heavily irrigated. As a result of differences in soil moisture and vegetation cover, there were large differences in the sensible and latent heat fluxes between the farm and steppe areas. Although there were site-to-site variations in the fluxes within the steppe and farm areas, these variations were generally small compared to the differences between the areas. The result is that, to a good approximation, during the day the measurement region can be considered to consist of two principal land types - a dry, hot steppe area with peak value of surface sensible heat flux of $\sim 300$ $\mathrm{W} / \mathrm{m}^{2}$ or more and a moist, cool farm area with flux values of $\sim 80 \mathrm{~W} / \mathrm{m}^{2}$ or less. 


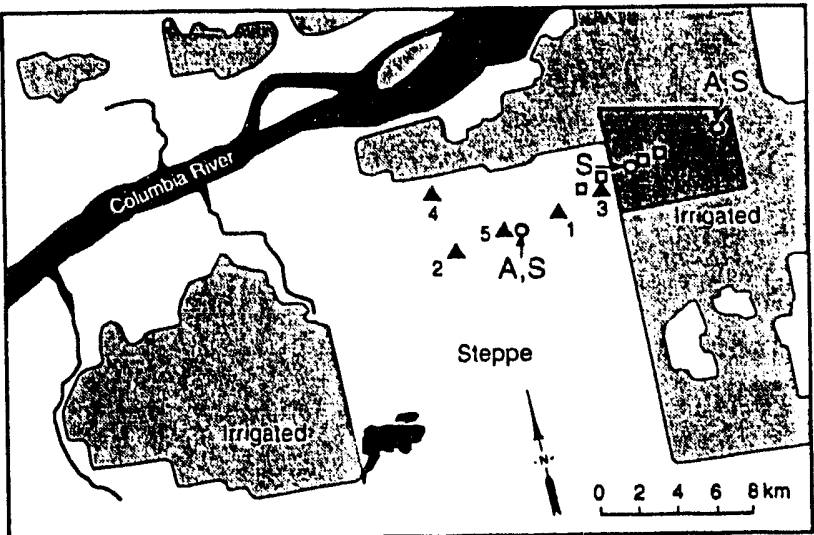

Fig. 1. Map of the experimental domain showing steppe and irrigated regions. Sodar locations are marked with an S, radiosonde release points with an A, surface meteorological stations by squares, and sensible heat flux measurement sites in the steppe by triangles.

The Columbia Gorge lies to the west of the experimental area. This major gap in the Cascade Range helps channel flow through the Gorge so that low-level winds over the area are generally southwesterly or westerly for much of the year. During the 1992 experiment westerly or southwesterly winds were observed on almost all days during the morning hours. If the winds were moderately strong in the morning they tended to persist for most of the day, and little change in wind direction was observed over the experimental domain. However, on several days the winds became light in the afternoon, and shifted from a southwesterly direction during the morning hours to north or northeasterly directions later in the morning and early afternoon over both the farm and steppe. On one day, June 11 , the wind remained out of the west southwest over the steppe for the whole day but switched to more northerly and northeasterly directions over the farm. This behavior is shown in Figure 2. On all days the depth of the mixed layer measured at two radiosonde locations, one in the farm and the other in the steppe, were generally similar despite the large differences in surface flux values.

\section{MODEL SIMULATIONS}

To help interpret the observations, we carried out a series of numerical modeling experiments using a mesoscale model. The numerical model used in this study is the Colorado State University Regional Atmospheric Modeling System (RAMS) (Trippoli and Cotton, 1982). RAMS is a three-dimensional, nonhydrostatic, primitive equation model with a

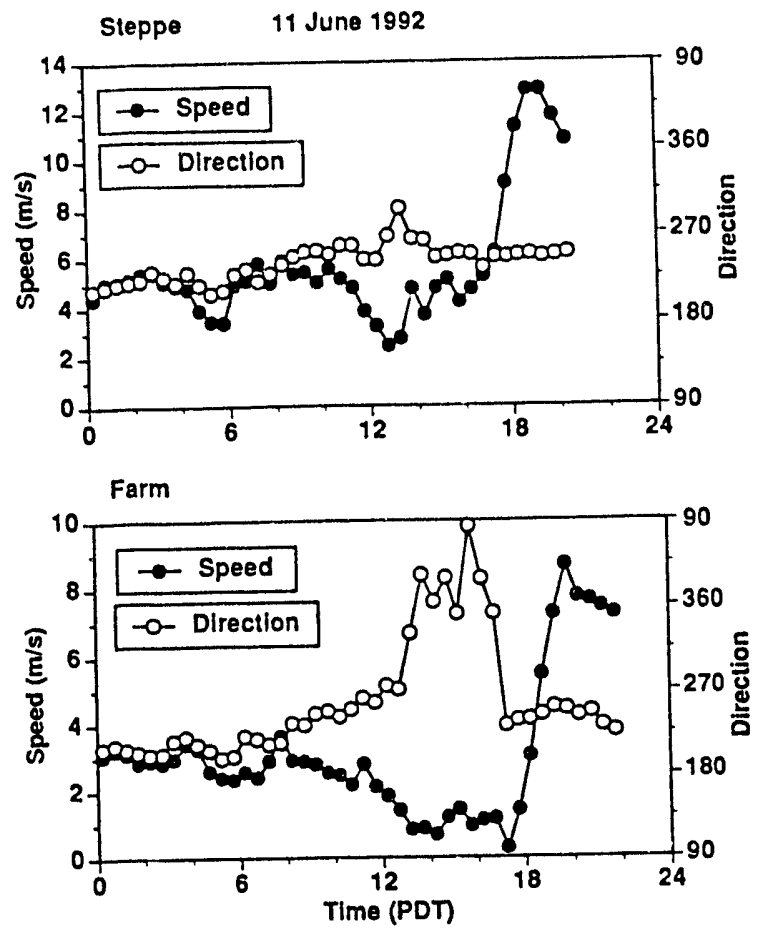

Fig. 2. Wind speeds and directions on June 11, 1992 over steppe (top) and farm (bottom), at heights of 9 $\mathrm{m}$ and $4 \mathrm{~m}$, respectively.

terrain-following coordinate system. The version of RAMS used for this study includes a prognostic turbulent kinetic (TKE) energy equation from which turbulent diffusion coefficients are determined following the approach of Mellor and Yamada (1982). We employed a nested grid configuration: the outermost domain, with a horizontal grid spacing of 8 $\mathrm{km}$, encompassed southern Washington and northern Oregon, and two nested grids of 2 and $1 \mathrm{~km}$ grid spacing were centered over the experiment site. In the vertical, the grid spacing varied between $30 \mathrm{~m}$ at the lowest model level, increased to $\sim 160 \mathrm{~m}$ at $1000 \mathrm{~m}$ and to $500 \mathrm{~m}$ at the top of the domain at $7280 \mathrm{~m}$. The topography and land use cover used in the model for the $2-\mathrm{km}$ grid are shown in Figure 3 . The experiment site is surrounded by gently sloping terrain for a radius of approximately $30 \mathrm{~km}$, beyond which more extreme terrain relief is found. Surface features in both the farm and steppe areas of the experiment region are well resolved by the $2-\mathrm{km}$ and $1-\mathrm{km}$ grids. The initial temperature sounding was based on data obtained from an airsonde release at 0600 Pacific Daylight Time on June 11; each simulation lasted for $10 \mathrm{~h}$.

For our reference simulation, we have assumed an ambient wind speed of $4 \mathrm{~m} / \mathrm{s}$ from the southwest, which corresponded with the conditions observed over 


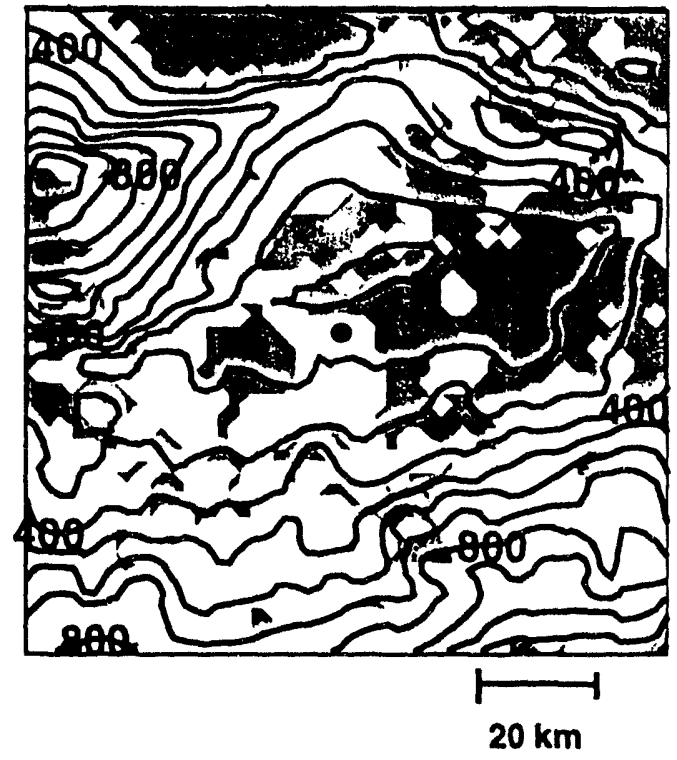

Fig. 3. Topography and vegetation for the $2-\mathrm{km}$ grid used in the modeling studies. The gray areas show irrigated farmland and portions of the Columbia River; the white areas are steppe. The dot in the center of the domain corresponds to the radiosonde and sodar location in the steppe.

the steppe on June 11. Figure 4 shows the nearsurface wind field at $15 \mathrm{~m}$ after 8 hours of simulated time. There is a region of strong divergence from the lowest terrain toward the higher terrain to the north and south. In addition, there is a marked shift in wind direction near the steppe-farm boundary. Over the steppe the winds blow from the west while over the farm they are from the north and northeast. This behavior agrees well with the observed behavior illustrated previously in Figure 2.

To identify the relative importance of synoptic, topographical, and surface influences, we carried out a series of additional simulations in which we varied one or more of these forcing mechanisms. Figure 5 shows results from a simulation in which surface characteristics were made uniform and similar to those found over the steppe area. There is again a region of divergence characterized by thermally forced upslope winds blowing toward the higher terrain. However, the wind direction shear observed at the steppe-farm boundary in the first simulation has disappeared. A comparison of Figures 4 and 5 clearly illustrates the importance of land-use contrasts in modifying the local wind fields. We repeated the first simulation but with flat topography. As anticipated, the welldefined divergence pattern is absent but secondary circulations arising from flux contrasts between farm

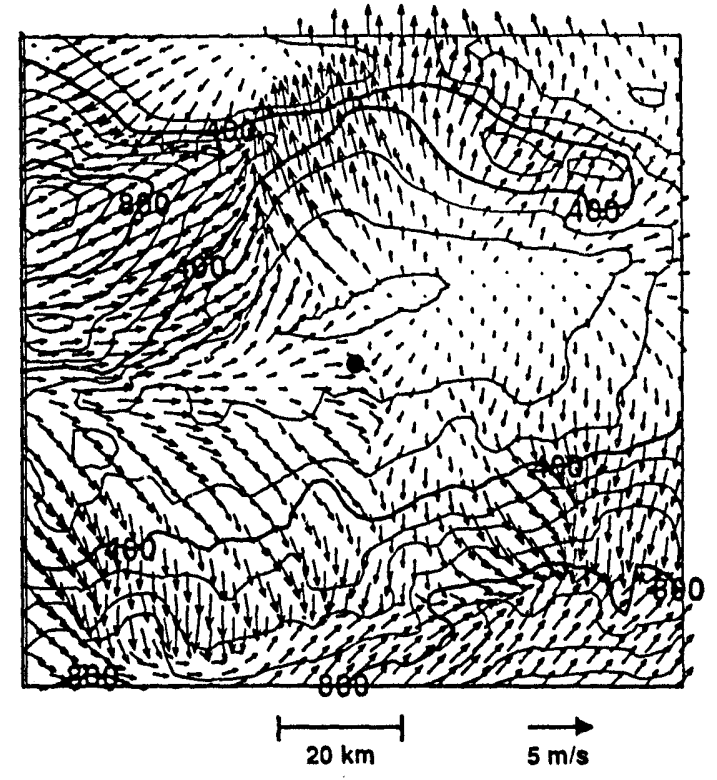

Fig. 4. Simulated near-surface wind field for $4 \mathrm{~m} / \mathrm{s}$ ambient wind from the southwest.

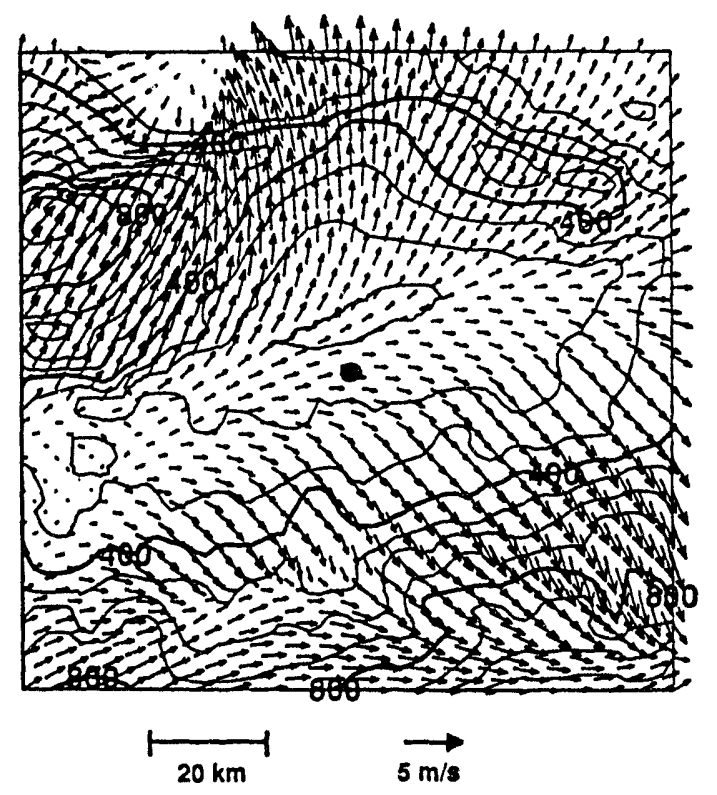

Fig. 5. As in Figure 4 but for uniform surface cover similar to that found over the steppe.

and steppe are easily seen. Finally, a simulation was carried out in which the ambient wind speed was increased to $8 \mathrm{~m} / \mathrm{s}$. In that case, except for some obvious terrain channeling, wind directions over the domain were quite uniform, in agreement with 
observations. For our reference case, Figure 6 shows the top of the mixed layer over the inner most domain, where the mixed layer is defined as the region in which the TKE is $>0.02 \mathrm{~m}^{2} \mathrm{~s}^{-2}$. Two features are significant. First, the deep mixed layer depth near the periphery of the figure is evidently associated with the enhanced production of TKE over elevated terrain. Second, over the flatter central region of the domain there are also significant variations in mixed layer depth but these variations are not well correlated with the surface characteristics immediately below. Advection can be shown to have a major influence on mixed layer depths, but the complex circulation patterns in the region make simple parameterizations of such effects difficult.

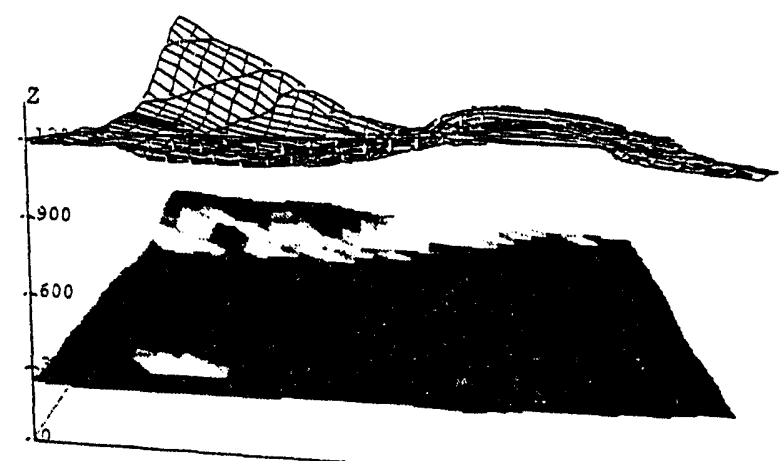

Fig. 6. Simulated mixed layer depth over the experimental area. The black areas show irrigated farm land; the gray areas are steppe; and the white areas are inland water.

\section{CONCLUSIONS}

While most previous modeling work has concentrated on surface inhomogeneities with scales well in excess of $10 \mathrm{~km}$, smaller scales of inhomogeneity are more likely to be encountered in real-world conditions. The present observational and numerical results show that significant PBL effects may arise with patches of $O(10 \mathrm{~km})$ and perhaps even less, which is consistent with the scaling argument developed by Shaw and Doran (1994). Terrain-driven secondary circulations and turbulence generation, coupled with the effects of land-use differences, may be even more important in modifying boundary layer structure. The present results imply that effective parameterizations of subgrid-scale features may have to take into account ambient winds, topographical features, flux differences between adjacent surface patches, and the sizes of the adjacent patches. The degree to which such features must be included will obviously depend on the specific boundary layer properties that are to be modeled, and this area remains relatively unexplored at this time.

\section{ACKNOWLEDGMENT}

This research was supported by the U.S. Department of Energy under Contract DE-AC06-76RLO 1830 at Pacific Northwest Laboratory under the auspices of the Atmospheric Radiation Measurement Program. Pacific Northwest Laboratory is operated for the U. S. Department of Energy by Battelle Memorial Institute.

\section{REFERENCES}

Avissar, R., and F. Chen, 1993: Development and analysis of prognostic equations for mesoscale kinetic energy and mesoscale (subgrid scale) fluxes for largescale atmospheric models. J. Atmos. Sci., 50, 3751-3774.

Mellor G. L., and T. Yamada, 1982: A hierarchy of turbulence closure models for planetary boundary layers. J. Atmos. Sci., 31, 1791-1806.

Segal, M., R. Avissar, M. C. McCumber and R. A. Pielke, 1988: Evaluations of vegetation effects on the generation and modification of mesoscale circulations. J. Atmos. Sci., 45, 2268-2292.

Shaw, W. J., and J. C. Doran, 1994: On the development of boundary layer secondary circulations resulting from horizontally varying surface heat flux. in Preprints, 21 st Conference on Agricultural and Forest Meteorology. San Diego, California.

Tripoli, G. J., and W. R. Cotton, 1982: The Colorado State University three-dimensional cloud/mesoscale model -- Part I: General theoretical framework and sensitivity experiments. $J$. de Rech. Atmos., 16 185-1307.

Yan, H., and R. A. Anthes, 1988: The effect of variations in surface moisture on mesoscale circulations. Mon. Wea. Rev., 116, 192-208. 

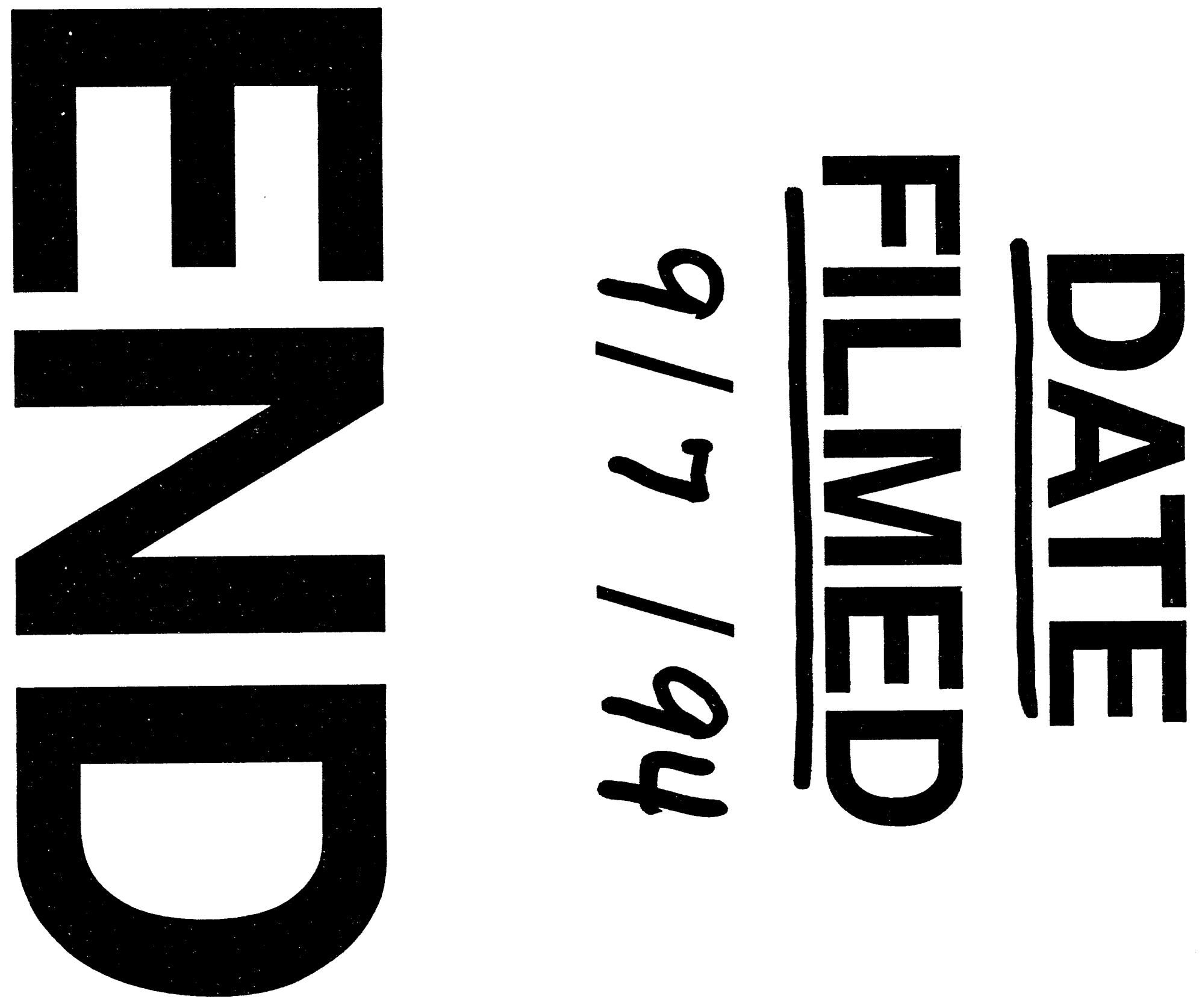
.

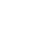

